\title{
Review
}

\section{The Class of the New by Richard Barbrook}

\author{
Christoph Hermann
}

Christoph Hermann is is a senior researcher at Forschungs- und Beratungsstelle Arbeitswelt (FORBA), the Working Life Research Centre in Vienna, Austria.

Richard Florida's Rise of the Creative Class' has become an academic bestseller in the United States and beyond. ${ }^{1}$ In his Class of the New Richard Barbrook contests the concept of the creative class on two major accounts: ${ }^{2}$ First, the scientific invention of new classes has a long history and can be traced back as far as Adam Smith's comments on the Nature and Cause of the Wealth of Nations. From this perspective Florida's concept is only the latest in a long chain of concepts with expiry dates. Second, the concept is highly ideological, while empirically and theoretically flawed.

Barbrook has assembled 86 definitions of new classes from the past 230 years. It seems that at each turning point in capitalist development, researchers have found evidence that a new class is emerging which, depending on the political intention of the author, will either lead capitalist society into a new phase of economic prosperity or overthrow the existing system and bring about socialism. In both cases the future will certainly be better than the past. Florida's creative class in no exception. Despite promoting postmodern values such as individuality and diversity, it is deeply modernist insofar as it promises a better world full of happy and self-sufficient workers. Perhaps the modernist optimism is rooted in a bleak technological determinism which, remarkably, seems to be shared by all these authors regardless of their political backgrounds. 'Over the past two centuries, the restructuring of working methods and the development of better machinery have been the driving forces of this economic system. Each wave of organisational and technological change has required another reordering of the hierarchical relationship between capital and labour. In successive generations, the concept of the new class has been used to analyse the impact of these processes upon the structures of modernity.'(page 20). The information and communication technologies and the world wide web which allegedly boosted workers' creativity, or, in a left version, their independence and cooperation, are only the latest examples of a long list of technological inventions.

Barbrook hopes to reveal continuities and discontinuities with his encompassing list of concepts.

'By analysing what has changed and what has remained the same, we come closer to comprehending the political and economic significance of this social prophecy in the present.' (page 19). 
Barbrook assembles a montage of quotations which is supposed 'to create its own meaning'(ibid). ${ }^{3}$ It would have been more interesting if he had analysed the role played by different class definitions as part of an ideological struggle over how the future of work is seen, including its division of labour and hierarchical structures, since such visions always work as a legitimation or de-legitimation of the existing system. As Barbrook notes, 'the new class is prefiguring today how everyone else will work and live tomorrow'(page 17). Given that writers of the left have been particularly active in these exercises in class definition, it would have been interesting to read a discussion of how they have imagined a future socialist world of work and to which degree these imaginations have inspired revolutionary forces.

Barbrook's second point is a more practical one. He takes the example of London to demonstrate how Florida's concept has been translated into a local development strategy, thereby simultaneously legitimising the existing order and giving hope for a better future. After a period of painful deindustrialisation, London, like so many other Western cities, has discovered the creative industries as its new source of competitive advantage in an increasingly globalised world. In contrast with many second- or thirdranking urban centres, London actually acquired its competitive advantages as one of the few global cities in Europe on the basis of its banking and finance sectors rather than its creative industries. Yet, according to a study published by the Greater London Authority in 2002, the media, cultural and computing sectors have grown faster in the 1990s than any other section of the local economy. After business services, the creative industries have become the second largest source of new jobs.

Barbrook quotes statisticians' estimates that in 2000 ten per cent of London's population were already members of the creative class, including artists, designers, programmers, technicians, writers, musicians, architects, actors, directors, copywriters and tailors, a proportion that, according to these sources, will continute to rise (page 33). This ten per cent is modest by Florida's standards (he estimates that creative workers make up for as much as a third of the American workforce), but Barbrook disputes even this number as empirically unsustainable.

'Crucially, the British government's employment surveys lumped together people with very different jobs under the same category because they happened to work in the same industry. When they were on the payroll of a film company, security guards were transformed into members of the Creative Class ... When they were selling artworks and antiques, old-fashioned shopkeepers were counted as part of the new class.' (ibid).

Confronted with the lack of statistical evidence, the defenders of the creative class have repeatedly argued that its significance lies in a qualitative change which cannot be measured quantitatively. Without empirical evidence the notion of the creative class becomes what it really is: 'feel-good rhetoric' or, more precisely, a deeply ideological concept. It gives super-exploited workers, many of whom do not even have unemployment insurance or pension coverage, a positive image to identify with while at the same time legitimising the neoliberal restructuring of London (pages 39-40). It

3 In producing a collage of definitions Barbrook follows the examples of Walter Benjamin and Humphrey Jennings. 
also helps to conceal the increasing social divisions among the urban population, including those between the super-rich and the super-poor creative workers, and the reality that many creative people can no longer afford to live in the creative city (ibid. 41).

But the concept of a creative class is not only empirically weak, it is also theoretically inadequate. The strongest and most original point in Barbrook's critique is when he reveals the limits of Florida's thesis by exposing it to the London experience. 'Ironically, this theorist draws the boundaries of the Creative Class not only too widely, but also too narrowly. On the one hand, he includes people doing routine tasks, which require little or no imagination within this sector. On the other hand, this theorist ignores the extent to which contemporary culture is a participatory phenomenon. Creativity isn't a monopoly of the Creative Class. The majority of the population, who earn their living outside this sector, can also be cultural producers. When Florida praises cities with hip music scenes, he misses that some the coolest people in their clubs and bars aren't members of his new class. For them, creativity is what happens when they're playing outside work.' (page 46).

Perhaps the deeper contradiction which Barbrook is pointing to is the dependence of capitalism on one kind of creativity to create new commodities and innovate production and work organisations, while at the same time restricting other kinds of creativity through exploitative production relations and commodification.

(c) Christoph Hermann, 2006 